\title{
Assessment of alternative land management practices using hydrological simulation and a decision support tool: Arborea agricultural region, Sardinia
}

\author{
P. Cau ${ }^{1}$ and C. Paniconi ${ }^{2}$ \\ ${ }^{1}$ Center for Advanced Studies, Research and Development in Sardinia (CRS4), Parco Scientifico e Tecnologico, POLARIS, \\ Edificio 1, C.P. 94, 09010 Pula (Cagliari), Italy \\ ${ }^{2}$ Institut National de la Recherche Scientifique - Centre Eau, Terre et Environnement (INRS-ETE), Université du Québec, \\ 490 de la Couronne, Québec, G1K 9A9, Canada
}

Received: 8 January 2007 - Published in Hydrol. Earth Syst. Sci. Discuss.: 10 April 2007

Revised: 8 August 2007 - Accepted: 16 November 2007 - Published: 23 November 2007

\begin{abstract}
Quantifying the impact of land use on water supply and quality is a primary focus of environmental management. In this work we apply a semidistributed hydrological model (SWAT) to predict the impact of different land management practices on water and agricultural chemical yield over a long period of time for a study site situated in the Arborea region of central Sardinia, Italy. The physical processes associated with water movement, crop growth, and nutrient cycling are directly modeled by SWAT. The model simulations are used to identify indicators that reflect critical processes related to the integrity and sustainability of the ecosystem. Specifically we focus on stream quality and quantity indicators associated with anthropogenic and natural sources of pollution. A multicriteria decision support system is then used to develop the analysis matrix where water quality and quantity indicators for the rivers, lagoons, and soil are combined with socio-economic variables. The DSS is used to assess four options involving alternative watersheds designated for intensive agriculture and dairy farming and the use or not of treated wastewater for irrigation. Our analysis suggests that of the four options, the most widely acceptable consists in the transfer of intensive agricultural practices to the larger watershed, which is less vulnerable, in tandem with wastewater reuse, which rates highly due to water scarcity in this region of the Mediterranean. More generally, the work demonstrates how both qualitative and quantitative methods and information can assist decision making in complex settings.
\end{abstract}

Correspondence to: $\mathrm{P}$. Cau

(plcau@crs4.it)

\section{Introduction}

\subsection{Context}

Water resources management is an important environmental problem in Mediterranean areas, where water demand is steadily increasing while available supply is limited. Nitrate and phosphorous levels in water bodies, both ground and surface, are also found to be increasing, due predominantly to agricultural activities, and economic mainstay for the island. Reducing diffuse water pollution is a strategic objective of European water policy, aimed at promoting sustainable farming practices, improving water quality, and preserving natural habitats. The European Union Nitrates Directive (91/676/EEC) requires member states to identify areas where groundwaters have nitrate concentrations exceeding $50 \mathrm{mg} / \mathrm{l}$ or are thought to be at risk of nitrate contamination. Areas thus identified are designated as "nitrate vulnerable zones" within which "action programmes" must be established to reduce and prevent further contamination. Due to land overexploitation and the high permeability of the soils, the shallow phreatic aquifer of the Arborea plain in central Sardinia is being polluted by nutrients, and the region has been designated as a nitrate vulnerable zone. Intensive dairy and grain farming are present on the territory. The deep aquifer, due to over pumping, is also contaminated by seawater intrusion. As a result, alternative land use strategies are being evaluated, including the transfer of the major agricultural activities away from the plain and into one of two adjacent watershed basins (see Fig. 1), and the installation of a water treatment plant downstream, with possible reutilization of the treated wastewater for irrigation.

Published by Copernicus Publications on behalf of the European Geosciences Union. 


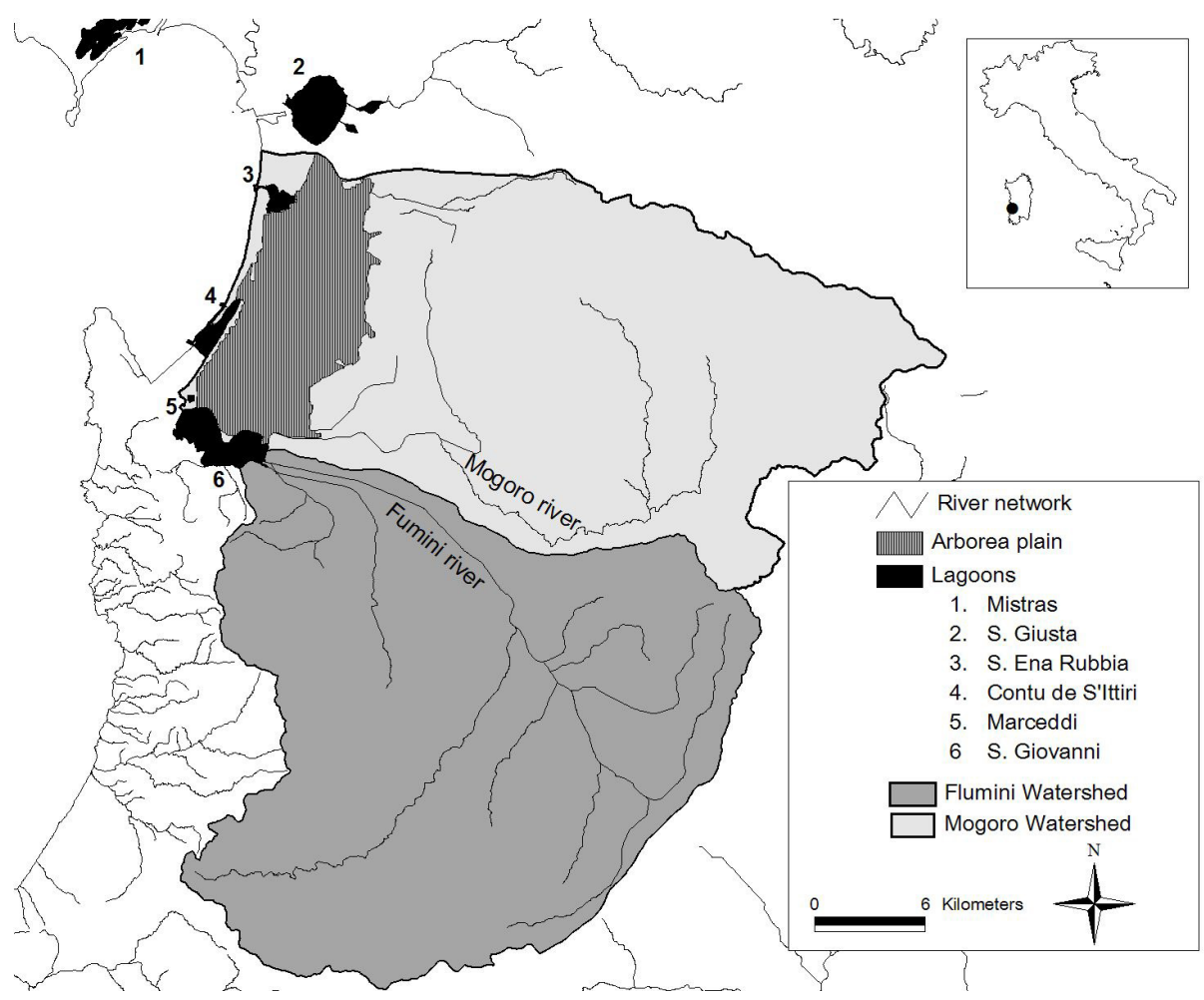

Fig. 1. Location of the study area.

\subsection{Description of the study area}

Situated in the western Mediterranean Sea, the climate of the Arborea plain is typical Mediterranean, with long, hot, dry summers and short, mild, rainy winters. The prevailing wind is north-westerly and blows over Sardinia in all seasons. Several natural permanent pools or lagoons (Mistras, Marceddi, S. Giovanni, S'Ena e Rubbia, Corru de S'Ittiri, and S. Giusta) and some seasonal ones which dry up completely during the summer are situated in the plain along the coast. The salt content varies significantly from one lagoon to another, the Mistras lagoon being the one with the highest salt content and the S. Giusta lagoon the lowest. The lagoons are recharged directly by rainfall, they collect surface runoff, and they interact with the rivers, groundwater, and the sea. The lagoons cover an area of about $60 \mathrm{~km}^{2}$, and comprise one of the largest wetlands in Europe. The main rivers (the Mogoro Diversi and the Flumini Mannu) are generally fast flowing, with a relatively high water volume in winter that reduces to a trickle in summer. Both rivers discharge their waters directly to the Marceddi lagoon (Fig. 1).

During the last decades, the plain has gone through profound changes. The current situation, not uncommon in Mediterranean areas, is the product of many years of poor management policies that often neglected the need to protect water and soil resources. Historically, the coastal part of the Arborea plain was an insalubrious morass, sparsely populated, and utilized mostly for pastoral activities. The morass also facilitated the spread of malaria, with about $43 \%$ of the local population suffering from this disease in 1934. The first reclamation was begun in 1812 and continued in 1912 when the Santa Giusta pond (one of the largest in the region) was dredged and the material was used to cover the extensive marshlands. But it was only after the enactment of the Serpioni laws (1924 and 1933) that reclamation was commenced for the entire plain. It was during this period that the town of Mussolinia was constructed, known today as Arborea. As a result of the reclamation work, the territory was covered with sandy soil possessing good drainage properties. In 1956 the Assegnatari Associati Arborea (3A) co-operative was established in the Arborea plain and soon became the main economic operator for the development of the territory. Zootechnical (milk production with more than 50000 cows) and agriculture (corns and grains) soon became predominant. Consequently, modern stock farms together with cultivation aimed at giving the right diet to the Frisona and Brown Swiss milk cows were established. The co-operative grew steadily in the years that followed (Fig. 2), with 3A becoming the leading dairy producer in Sardinia and one of the most important dairy firms in Italy. The company is made up of 248 partners who are owner-managers of small livestock dairy farms, and today it generates about $85 \%$ of the local income.

A more recent economic activity of increasing importance, and one that draws on the traditions and culture of the local 


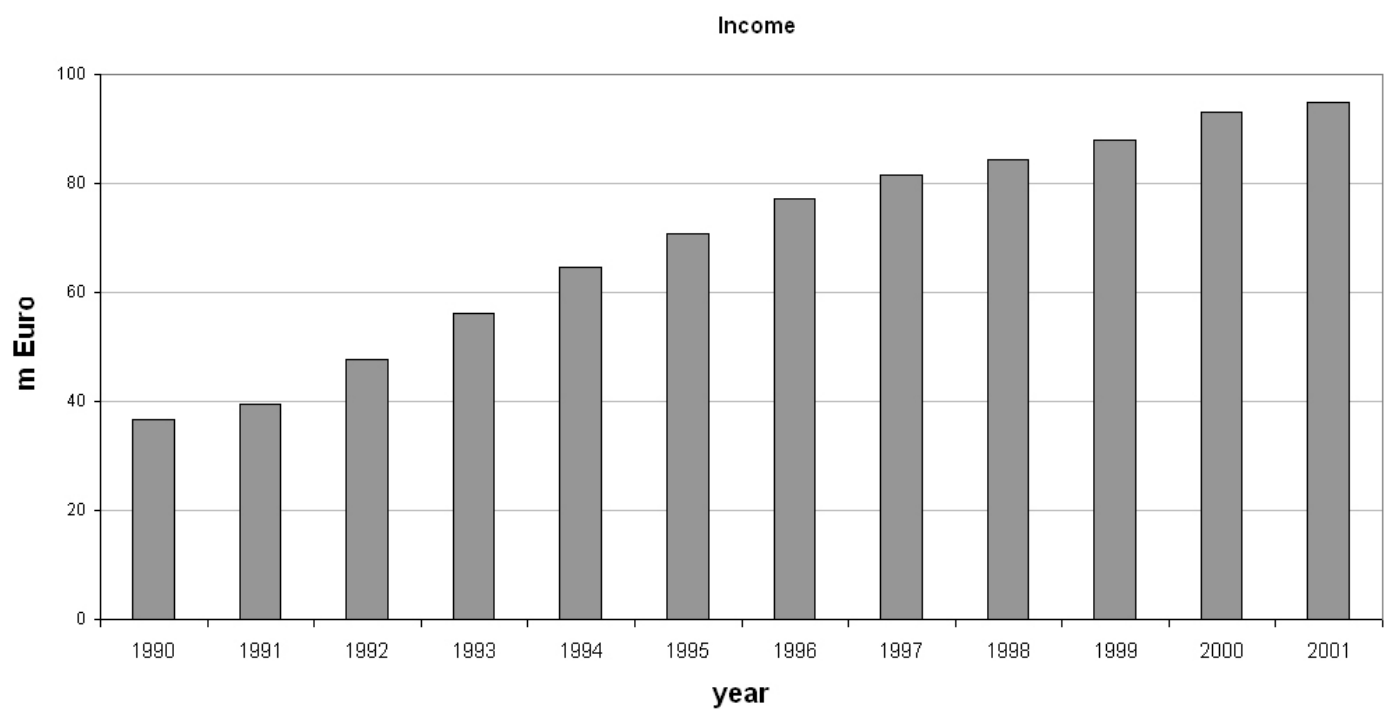

Fig. 2. Assegnatari Associati Arborea (3A) co-operative income in the period 1990-2001.

population, is fish farming, with two fisheries present in the lagoons. The fishermen are attentive to the conservation of the habitat and the management of the lagoons, and it is easy to appreciate how these can be adversely impacted by agricultural activities in the plain and further upstream.

\subsection{Objectives of the study}

Adequate water supply is a major problem in Mediterranean areas, with its hot dry summers and recurring droughts. The most recent prolonged drought (ending in 2003) led to severe rationing measures on urban, agricultural, and industrial water use. A substantial increase in groundwater withdrawal, much of it unregulated, has consequently been documented, especially along coastal areas. The aquifer system in the Arborea region is comprised of two main units, a shallow phreatic aquifer (few tens of meters) and a deeper aquifer (few hundreds of meters), separated by an aquitard of variable thickness. Due to inadequate water management policies and aquifer overpumping, the lower aquifer unit has been heavily contaminated by seawater intrusion. Because of the high permeability of the soil used to cover the morass, the shallow phreatic aquifer is also polluted, in this case by fertilizers, pesticides, and nitrates from the zootechnical and agricultural activities. Thus soils, groundwaters, streams, and lagoons are highly impacted from the intensive water use activities in the Arborea region. To reduce the impact of the fertilizers and pesticides on the phreatic aquifer of the Arborea plain, agro-zootechnical production in the region needs to be limited and/or wastewater needs to be collected and routed to a treatment plant.

Due to the economic importance of the farming activities, the land use options that are being evaluated to alleviate water contamination, without unduly harming or altering the socio-economic tissue of the region, include the transfer of much of the intensive dairy and grain farming to one of the adjacent watershed basins (the Mogoro or the Flumini), together with wastewater treatment, for which reuse of the wastewater for irrigation is also being considered. To assess these options, we will make use of a process-based simulation model and a decision support system, two tools that are increasingly being used in tandem because they enable analysis of water management and planning issues based on complex environmental, economic, and social parameters (e.g. Abel et al., 1992; Watkins and McKinney, 1995; Fedra and Jamieson, 1996; Heinemann et al., 2002; Chowdary et al., 2005). Decision support systems provide a framework for analyzing management and policy options based on diverse data, deriving in part, for our application, from hydrological simulation models. The hydrological model SWAT will be employed to simulate the basin water budgets and river nitrate and pesticide levels arising from current and hypothesized land management practices. Since both the Flumini and Mogoro basins drain into the Marceddi lagoon, today used as a fishing reservoir, the water quality impact on the rivers is a significant parameter in the assessment. The water budget is an important variable because the increased irrigation (with or without treated wastewater) on the watersheds to support the relocated agricultural activities may increase streamflow and thus adversely impact the salinity levels in the lagoon needed to sustain the fisheries. The results from the hydrological model will be fed into a decision support system, together with values reflecting various relevant socio-economic parameters, to obtain an overall assessment of the different land management options being considered. 


\section{Methodology}

\subsection{SWAT model}

The hydrological model used is the Soil and Water Assessment Tool (SWAT), version 2000 (Di Luzio et al., 2001), a watershed-scale model developed by the USDA Agricultural Research Service (ARS). SWAT can be used to predict the impact of land management practices on water, sediment, and agricultural chemical yields in large complex watersheds with varying soils, land use, and management conditions over long periods of time. The physical processes associated with water movement, sediment movement, crop growth, nutrient cycling, and other phenomena are directly modeled by SWAT (Neitsch et al., 2001). SWAT provides water balance estimates at the catchment scale and simulates the gradual build up of nitrates, phosphorous, and pesticides on downstream water bodies. The fate and transport of nutrients and pesticides in a watershed depends on the transformations the compounds undergo in the soil (land phase) and stream environment (routing phase). SWAT models the complete nutrient cycle for nitrogen and phosphorus as well as the degradation of pesticides within each hydrologic response unit (HRU) of the watershed. Hydrologic response units are portions of subbasins that possess unique soil/land use/management attributes. This subdivision of a watershed enables the model to reflect differences in evapotranspiration, runoff, movement and transformation of chemicals, etc., for various crops and soils. This increases accuracy and gives a much better physical description of the catchment's water balance and water quality.

Hydrological processes are first simulated in SWAT for the land phase at the HRU spatial unit. This yields the water, sediment, nutrient, and pesticide loadings to the main channel in each subbasin. In a second phase, the water, sediments, etc are routed through the channel network of the watershed to the outlet. For each subbasin there is one reach, one outlet, and many HRUs. Water quality and quantity states are given for each outlet at a daily temporal scale.

The nitrogen cycle, modeled by SWAT, is a dynamic system that includes the water, atmosphere and soil. Nitrogen's ability to vary its valence state makes it a highly mobile element, and thus predicting the movement of different nitrogen compounds in the soil is critical to the successful management of this element in the environment. The three major forms of nitrogen in mineral soils are organic nitrogen associated with humus, mineral forms of nitrogen held by soil colloids, and mineral forms of nitrogen in solution. SWAT allows nitrogen to be added to the soil by fertilizer, manure, or residue application, fixation by symbiotic or nonsymbiotic bacteria, and rain, while it can be removed from the soil by plant uptake, leaching, volatilization, denitrification, and erosion (Neitsch et al., 2001). Although plant phosphorus demand is considerably less than nitrogen demand, and its solubility is limited in most environments, phosphorus is also required for many essential functions. The most important of these is its role in energy storage and transfer. Energy obtained from photosynthesis and metabolism of carbohydrates is stored in phosphorus compounds for later use in growth and reproductive processes. The three major forms of phosphorus in mineral soils modeled by SWAT are organic phosphorus associated with humus, insoluble forms of mineral phosphorus, and plant-available phosphorus in soil. Phosphorus may be added to the soil by fertilizer, manure, or residue application. Phosphorus combines with other ions to form a number of insoluble compounds that precipitate out of solution. These characteristics contribute to a buildup of phosphorus near the soil surface that is readily available for plant uptake, erosion, and transport in surface runoff. Sharpley and Syers (1979) observed that surface runoff is the primary mechanism by which phosphorus is exported from most catchments.

\subsection{MULINO DSS}

The decision support system used in this study is the MULINO-DSS (mDSS), a DSS developed within the context of an international project on MULtisectorial, INtegrated, Operational decision support for sustainable use of water resources at the catchment scale (Giupponi et al., 2004). mDSS is based on the Driving forces-Pressures-State-ImpactResponses (DPSIR) framework, introduced by the European Environmental Agency for environmental monitoring purposes. This approach is useful in conceptualizing and formalizing the problem at hand. The conceptual phase consists in the identification of the DPS chains and the resulting indicators. The decision problem is therefore described and the cause-effect relation between the relevant socio-economic and environmental indicators is assessed. This task is particularly complex in water resources conflicts where the lack of a multisectorial perspective can result in socio-economic damages to the different local users. The multicriteria decision analysis in mDSS consists in comparing a limited number of options, described by their attributes. An analysis matrix is constructed which contains the raw performance measures of the different options. The different options are then compared using a standardization procedure to generate values on a uniform scale. Since the multiple option performances are to be reduced to a single value or score, decision rules based on aggregation procedures are applied (Mysiak et al., 2005).

The decision context for the Arborea study has been conceptualized using the DPSIR approach, identifying the socioeconomic and environmental indicators considered important to this problem. The four land use options assessed in the mDSS are:

Option 1. Land exploitation of the Mogoro basin (i.e. transfer of main agricultural activities from the Arborea plain to the Mogoro watershed) and reuse of treated wastewater 
(from a water treatment plant to be built downstream of the basin) for irrigation;

Option 2. Land exploitation of the Mogoro basin and no reuse of treated wastewater (in this case the treated wastewater is discharged directly to the river);

Option 3. Land exploitation of the Flumini basin and reuse of treated wastewater for irrigation;

Option 4. Land exploitation of the Flumini basin and no reuse of treated wastewater.

The end users or stakeholders involved in the decision process include the regional authorities for water resources management, the local municipalities, the dairy farm association ( $3 \mathrm{~A}$ cooperative), private farmers, and the managers of the lagoon fisheries.

The driving forces are the need to use the land for dairy and grain farming; the pressures are the use of fertilizers and pesticides, the water demand for irrigation, other agricultural activities that produce or release nutrients, and the release of wastewater from the treatment plant; the states are the water volumes needed for irrigation to optimize crop growth, the levels of nitrates, phosphorous, and pesticides in the rivers, the average streamflow volume and its variability, the cost of the treatment plant and irrigation infrastructure, the cost of irrigation water, and the risk for farmers in transferring their production activities, including potential conflicts between users and income losses/gains. The water volume for optimal crop growth is estimated by SWAT by supplying the soil water deficit on a daily basis. Streamflow and phosphorous, pesticide, and nitrate concentrations in the rivers are also computed by SWAT at the outlet of the Mogoro and Flumini basins. The economic parameters are estimated by examining costs and benefits. The cost of a treatment plant is assessed on the basis of the pollutant load generated from the zootechnical compartment, using the empirical formula $C t=200 \times A E$ where $C t$ is the cost (Euro) and $A E$ is the load expressed in equivalent inhabitants (AATO, 2001). The cost of the irrigation pipelines depends on their length, the desired flow rate, and the geomorphology of the territory. This cost has likewise been assessed using empirical formulas and values from the literature (Milano, 1996). In southern Italy the cost to the community of $1 \mathrm{~m}^{3}$ of treated water is about 0.25 Euro, while fresh water costs about $0.45 \mathrm{Euro} / \mathrm{m}^{3}$. Other socio-economic indices (the risk for farmers in transferring their production activities, including potential conflicts between users and income losses/gains) were assessed through questionnaires aimed at assessing how stakeholders and local municipalities perceive the alternative management policies. These questionnaire responses were then transformed into numerical form for input to the evaluation matrix.

\subsection{Model setup and calibration}

\subsubsection{Soil and land cover}

The watershed of the Flumini Mannu river is $613 \mathrm{~km}^{2}$ and varies in elevation from 0 to $1236 \mathrm{~m}$ a.s.l. About $60 \%$ of its territory can be used for agriculture, about $5 \%$ is used for pasture, and the rest is characterized by forest and bush. The watershed of the Mogoro Diversi river is $369 \mathrm{~km}^{2}$, and its topography ranges from 0 to $760 \mathrm{~m}$ a.s.l. About $65 \%$ of its territory can be used for agriculture, about $12 \%$ is used for pasture, and the rest is forest and bush. The Flumini Mannu and Mogoro Diversi rivers discharge their waters to the Marceddi lagoon. Acquisition and analysis of extensive soil and land use data for the Mogoro and Flumini basins was carried out with a geographical information system using data formats and procedures compatible with SWAT. The first step was to partition the watersheds into subunits. SWAT allows several different subunits or objects to be defined within a watershed: subbasins, HRUs, ponds, reaches/channels, and wetlands. Information about the geometry of the basins was extracted from a $400 \mathrm{~m}$ elevation grid and the river network. The minimum drainage area assessed by the AVSWAT preprocessing tool was 2500 ha. With this threshold the Mogoro and Flumini watersheds were subdivided into 7 and 11 subbasins, respectively.

Information about soil properties was obtained from a 1:250 000 soil vector map where each cartographic unit was associated with one or two delineations corresponding to subgroups of the USDA soil taxonomy. For the characterization of the geopedologic facies of the area we referred to the Soil Map of Sardinia (Aru et al., 1991) and the Land Classification for Irrigation of Sardinia (Arangino et al., 1986). From these studies, a collection and evaluation of the irrigation needs, based on a census of all agronomic and geopedological elements, was derived. About 40 representative soil profiles were recognized, described, and classified according to USDA and FAO guidelines. Physical and hydrogeological properties of the soil profiles were related to the corresponding cartographic units of the pedologic map using taxonomy categories. Classical pedotransfer functions were used to calculate dependent variables (field capacity, permanent wilting point, Available Water Capacity, saturated hydraulic conductivity) from the percentages of sand, silt, and clay content. Complementary information was obtained, for the same soil classes, using the State Soil Geographic (STATSGO) database (USDA and NRCS, 1994). All of this information was cast into a soil database formatted for SWAT. This geodatabase, built on the spatial linkage between the soil map and the soil database, drastically reduced the amount of GIS initialization.

Land cover significantly affects the water cycle via its influence on rainfall interception and the partitioning of this precipitation into infiltration and runoff, and via the influence of surface albedo, surface roughness, and vegetation density 


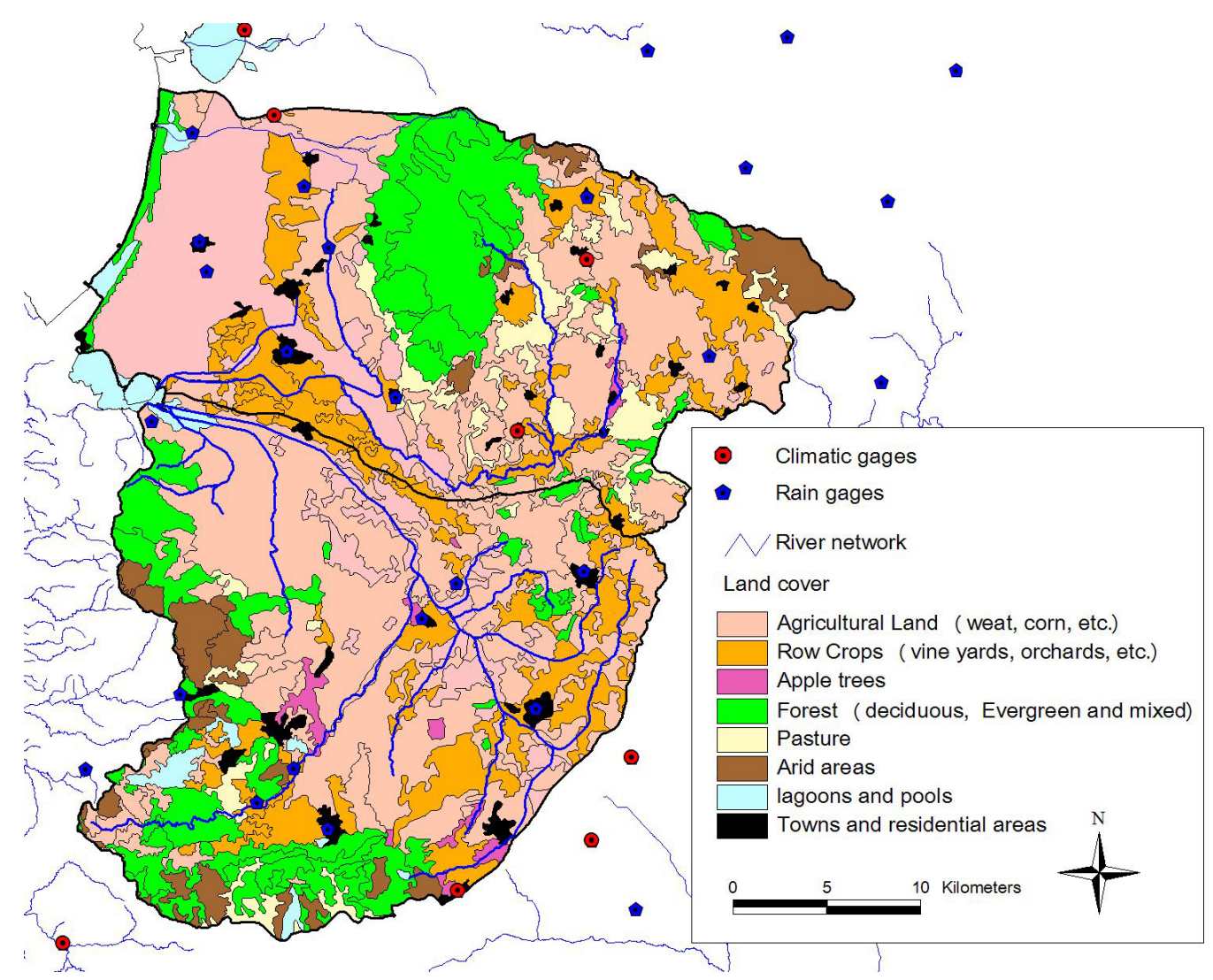

Fig. 3. Land cover map for the Flumini and Mogoro basins.

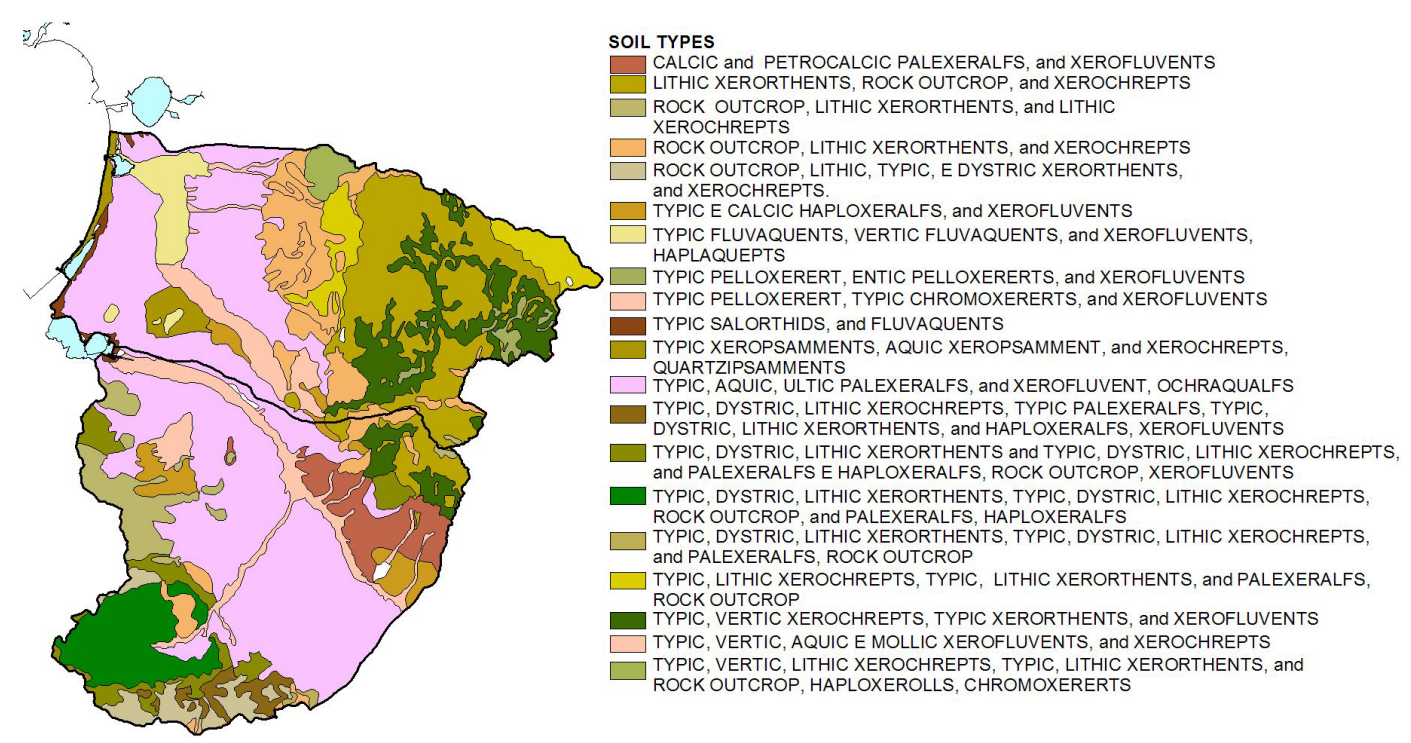

Fig. 4. Soil map for the Flumini and Mogoro basins. The two basins are characterized by a large variety of soil types. Each soil type is characterized by at least one layer (up to ten layers) and for each layer SWAT requires 16 soil physical characteristics (sand, silt, and clay content; hydrologic group; hydraulic conductivity; $A W C$; $C N$; etc.). 
Table 1. Monthly (subscripts 1 January to 12 December) analysis of $P W / W$ (probability that a wet day is followed by a wet day) and $P D / W$ (probability that a dry day is followed by a wet day).

\begin{tabular}{llllllllllll}
\hline$P W / W_{1}$ & $P W / W_{2}$ & $P W / W_{3}$ & $P W / W_{4}$ & $P W / W_{5}$ & $P W / W_{6}$ & $P W / W_{7}$ & $P W / W_{8}$ & $P W / W_{9}$ & $P W / W_{10}$ & $P W / W_{11}$ & $P W / W_{12}$ \\
0.5792 & 0.5736 & 0.5261 & 0.4432 & 0.4160 & 0.3190 & 0.2127 & 0.2962 & 0.3588 & 0.4875 & 0.5736 & 0.6011 \\
\hline$P D / W_{1}$ & $P D / W_{2}$ & $P D / W_{3}$ & $P D / W_{4}$ & $P D / W_{5}$ & $P D / W_{6}$ & $P D / W_{7}$ & $P D / W_{8}$ & $P D / W_{9}$ & $P D / W_{10}$ & $P D / W_{11}$ & $P D / W_{12}$ \\
0.2041 & 0.2114 & 0.1728 & 0.1644 & 0.1005 & 0.0574 & 0.0223 & 0.0372 & 0.1119 & 0.1871 & 0.2325 & 0.2638 \\
\hline
\end{tabular}

on evapotranspiration. In this study we used the CORINE Land Cover 1:100 000 vector map (EEA, 2000), a geographical database describing vegetation and land use in 44 classes grouped into three nomenclature levels. The resulting soil and land use maps for the Mogoro and Flumini watersheds are shown in Figs. 3 and 4. With this data, the Mogoro and Flumini subbasins were subdivided into 125 and 276 HRUs, respectively.

\subsubsection{Climate characterization}

The climate of the Arborea region is typical Mediterranean with hot dry summers and short rainy winters, except at high altitudes, and prevailing north-westerly winds. Average annual temperatures range from $18^{\circ} \mathrm{C}$ along the coast to $14^{\circ} \mathrm{C}$ inland. Temperature and solar radiation data were gathered from 7 climatic gages within the study area (Fig. 3). Annual average rainfall is $680 \mathrm{~mm}$, with a peak in December and a minimum in July. The SWAT model requires daily precipitation records, but the available pluviometric data for Sardinia is accessible on a monthly basis (EAF, 1996). To downscale the monthly data to synthetic daily precipitation time series, various alternatives were analyzed (Cau et al., 2002). The approach selected is a variation of the method proposed by De Groen and Savenije (2000) based on Markov chains. A similar approach (Nicks, 1974) is also used in SWAT to generate synthetic precipitation records on a daily basis. The generator works in two steps. First it determines if day $i$ is wet or dry: a random number $r_{o}$, between 0 and 1 , is generated and compared with $P W / W$ (probability that a wet day is followed by a wet day) if day $(i--1)$ is wet, or conversely with $P D / W$ (probability that a dry day is followed by a wet day) if day $(i--1)$ is dry. The following skewed distribution is then used to generate the precipitation amount:

$$
R=\mu+2 \frac{\sigma}{g}\left\{\left[\left(\mathrm{SND}-\frac{g}{6}\right)\left(\frac{g}{6}\right)+1\right]^{3}-1\right\}
$$

where $\mathrm{SND}=\cos \left(6.238 r_{2}\right)\left(-2 \ln r_{1}\right)^{1 / 2}$ is the normal deviate calculated for the day, $R$ is the amount $(\mathrm{mm})$ of daily rainfall on a given day, $\mu$ is the mean daily rainfall $(\mathrm{mm})$ for the month, $\sigma$ is the standard deviation of daily rainfall $(\mathrm{mm}), g$ is the skew coefficient for daily precipitation in the month, and $r_{1}$ and $r_{2}$ are random numbers. To calculate, for each station and each month of the year, the probability of a wet day to be followed by another wet day $(P W / W)$ or, conversely, a dry day by a wet one $(P D / W)$, we used the available daily data registered on a cluster of 175 rain gages throughout Sardinia with at least 30 years of data within the time period of interest. The daily synthetic precipitation for each month of each year of each station was then scaled to match the monthly registered rainfall. In this way, the data series for the 20 rainfall gages closest to the two basins under study (Fig. 3) were downscaled to daily data series. The AVSWAT GIS interface reads the location of the climatic and rainfall gages and automatically associates to each HRU the nearest corresponding data time series. Table 1 reports the $P W / W$ and $P D / W$ values for the study area.

Precipitation is the main driver of hydrological processes, and SWAT outputs greatly depend on how accurate the precipitation data is. The model has been run with the generated daily time series and with measured precipitation for the Sardinian basins which contain operational stations (Cau et al., 2002). The model outputs were then compared in order to estimate the uncertainty introduced by such a downscaling procedure. The water budget results for a 20 -year simulation period showed an average difference of $7 \%$ (with a range from $0.1 \%$ to $20 \%$ ). Summer periods, characterized by few but intense events, were the most critical. The correlation coefficient for monthly water budget estimates using measured and synthetic data was 0.94 , with no systematic error.

\subsubsection{Scenarios}

The SWAT model was run on both the Mogoro and Flumini basins to evaluate the water cycle and the fate of nutrients and pesticides for the following scenarios:

1. current conditions (no intensive agriculture on the basins, no wastewater reuse);

2. land exploitation with reuse of treated water (DSS options 1 and 3);

3. land exploitation and no reuse of the treated water (DSS options 2 and 4 ).

SWAT allows very detailed land management information to be incorporated into a simulation. Management operations control the plant growth cycle, the timing of fertilizer and pesticide applications, and the removal of plant biomass on a daily basis and HRU spatial scale. 


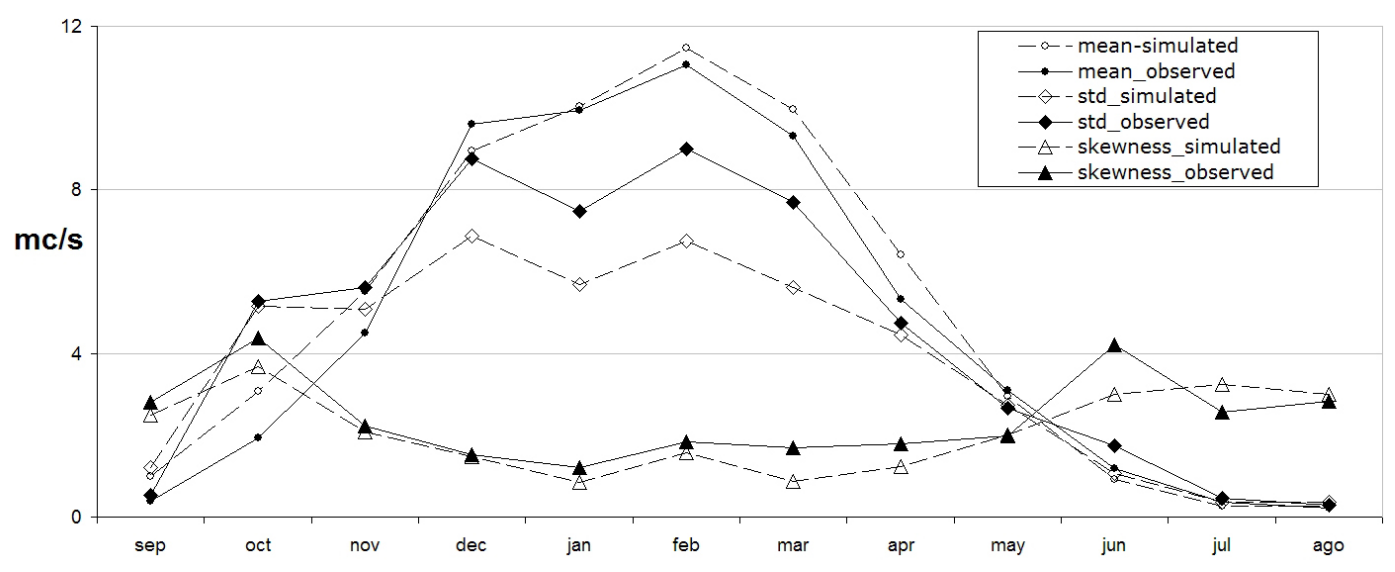

Fig. 5. Comparison of measured and simulated monthly streamflow statistics (mean, standard deviation, and skewness) for the 70-year regional calibration.

The CORINE land cover possesses little information about land management practices and its changes (e.g. seasonal and yearly). Furthermore its low spatial resolution is not ideal when examining intensive agriculture applied at a parcel scale. Diffuse pressures must be consequently assessed using heterogeneous information sources. In this study a part of the work was to integrate and cross validate the land use spatial information of the CORINE map (to each combination of land use/soil there corresponds 1 HRU within the subbasin) with information from regional and local agencies about agricultural practices (areas cultivated, crop types, etc) at the local scale. From this investigation we were able to obtain data concerning fertilizer and pesticide types and quantities in each subbasin that could be input to the model.

In our land exploitation scenarios we focused on a $20 \mathrm{~km}^{2}$ parcel that is to be allocated, in the 4 options, to the new agricultural practices. The auto irrigation initialisation option in SWAT was used; this operation initialises irrigation within the HRU. Auto irrigation applies water whenever the plant experiences a user-specified level of water stress. Corn and grain crops were considered. For each day of simulation, potential plant growth (i.e. plant growth under ideal growing conditions) is calculated. Ideal growing conditions consist of adequate water and nutrient supply and a favourable climate, and differences in growth between plant species are defined by the parameters contained in the plant growth database (Neitsch et al., 2001).

Two types of fertilizers were applied, 18-46-00 and 4600-00. These are characterized by a fraction of mineral $\mathrm{N}$ $\left(\mathrm{NO}_{3}\right.$ and $\left.\mathrm{NH}_{4}\right)$ in fertilizer ( $\mathrm{kg}$ min-N/kg fertilizer) equal to 0.18 and to 0.46 , respectively, and a fraction of mineral $\mathrm{P}$ in fertilizer ( $\mathrm{kg} \mathrm{min}-\mathrm{P} / \mathrm{kg}$ fertilizer) equal to 0.202 and to 0.0 , respectively. In the model $120 \mathrm{~kg} / \mathrm{ha}$ of $18-46-00$ fertilizer was applied in January, while $60 \mathrm{~kg} / \mathrm{ha}$ of 46-00-00 was applied in February. The pesticide used was plus-2, applied at the end of June. Pesticides are toxic by design, and there is a natural concern about their impact on human health and environmental quality. The fate and transport of a pesticide is governed by properties such as solubility in water, volatility, and ease of degradation. The algorithms that SWAT uses to model pesticide movement and fate are adapted from GLEAMS (Leonard et al., 1987).

\subsubsection{Calibration}

The model calibration followed a regional scale approach. The soil and land cover parameterizations described in section 2.3.1 are not restricted to a single watershed, as similar soil and land cover types are found in different basins of the region. All available streamflow data, from a total of 31 gages within watersheds adjacent to the Flumini and Mogoro basins, were used for the calibration of the model (Cau et al., 2002). Monthly streamflow and reservoir water level historical records were used as control values. The soil parameters adjusted during the calibration process, within ranges suggested in the literature, were AWC (available water capacity, \pm 0.04 ), $C N$ (curve number, $\pm 10 \%$ ), and ESCO (a compensation factor that controls the evapotranspiration, up to 1) (Eckhardt and Arnold, 2001; Vandenberghe et al., 2001). A total of 120 calibration parameters were activated (40 soil profiles $\times 3$ parameters). These parameters affect the partitioning between baseflow, runoff, percolation, and evapotranspiration, as well as the transport of sediments, nutrients, and pesticides. Changes to the values of these parameters were accepted only if an overall improvement in streamflow was achieved compared to observed data. This was determined using the Nash-Sutcliffe index

$K_{N S}=1-\left(\frac{\sum_{i=1}^{N}\left(Q_{1, i}-Q_{2, i}\right)^{2}}{\sum_{i=1}^{N}\left(Q_{1, i}-\bar{Q}_{1}\right)^{2}}\right)$ 


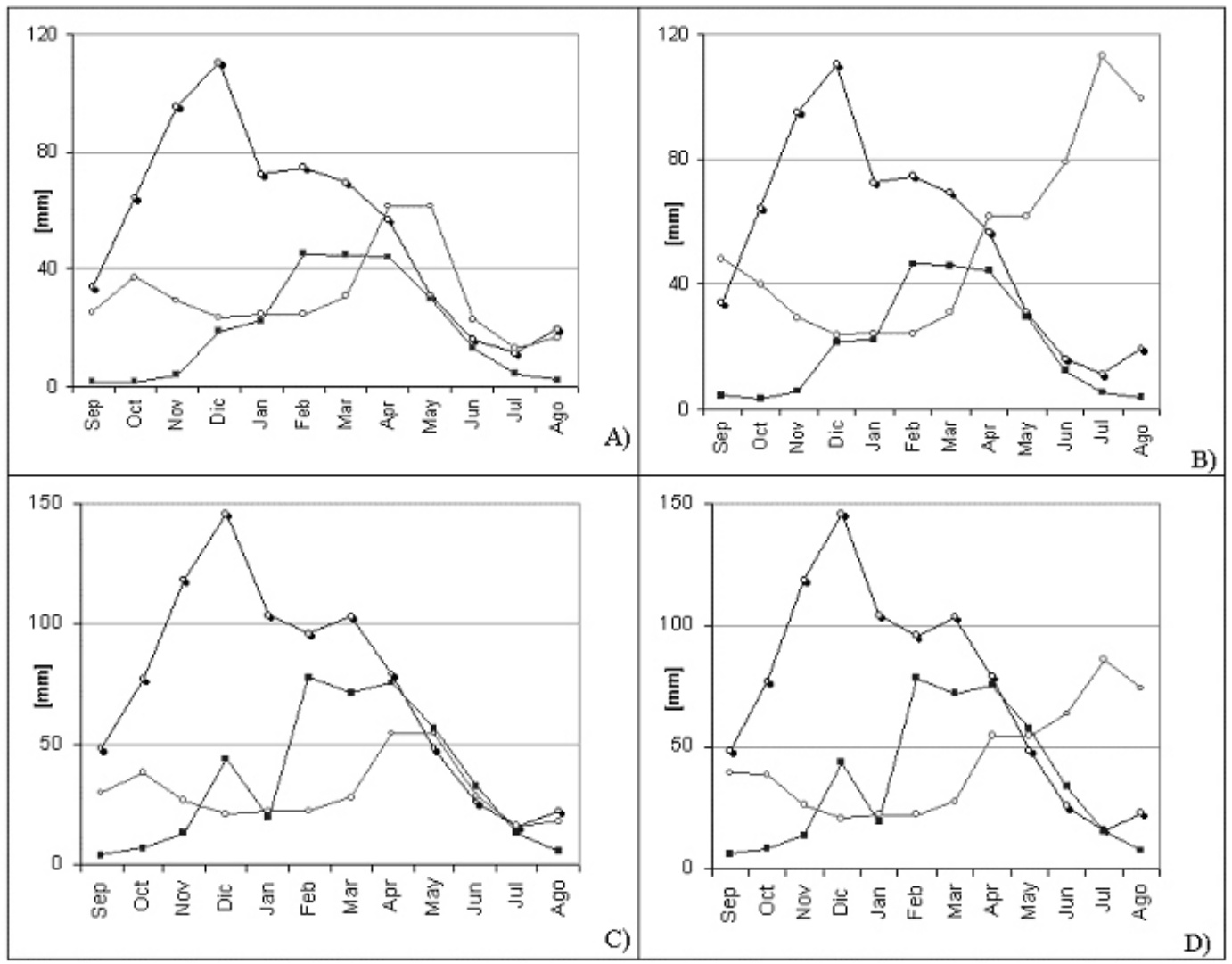

Fig. 6. Water budget calculation [mm/month] for the case of land exploitation (right) and for current land use (left) for the Flumini (above) and Mogoro (below) basins. While precipitation is unchanged, evapotranspiration (line with empty points) and streamflow (line with full points) are affected by the new management practices.

where $N$ is the number of years of observed streamflow data (70 in our case), $Q_{1, i}$ is the observed streamflow for year $i$, and $Q_{2, i}$ is the corresponding simulated streamflow. The Nash-Sutcliffe index ranges between $-\infty$ and 1 , with a perfect match $\left(K_{N S}=1\right)$ when $Q_{1, i}=Q_{2, i}$ for all $i$.

The calibration proceeded in the following manner: 1 (initial state), the SWAT model was run on 16 watersheds to obtain an initial comparison between simulated and observed streamflows; 2 (calibration), a subset of 3 watersheds possessing all of the soil profiles was used to calibrate the three soil parameters; 3 (validation), the adjusted parameters were accepted only if they improved the quality of the simulation for all 16 watersheds compared to the initial state.

The best-fit parameter values for our model implementation at a regional scale produced a Nash-Sutcliffe index of 0.77 , indicating a reasonably good match between simulated and observed streamflow rates. In Fig. 5 we also compare the measured and simulated monthly streamflow statistics (mean, standard deviation, and skewness) for the 70-year regional calibration. The annually averaged streamflow values of model output and measured data for the 70-year time period were 5.0 and $4.7 \mathrm{~m}^{3} / \mathrm{s}$, respectively, while the annually averaged standard deviations were 3.8 and $4.5 \mathrm{~m}^{3} / \mathrm{s}$, respec- tively. In several simulations using monthly streamflow data we were also able to accurately capture the timing and magnitude of seasonal water yields (Cau et al., 2002).

\section{Results}

\subsection{Hydrological model simulations}

In Fig. 6 the water balance of the Flumini and Mogoro basins is shown for cases 1 and 2 . The water balance results for case 3 were very similar to those for case 2 . The irrigation practices applied by the model have significantly affected the water balance. Real evapotranspiration increases because more soil water becomes available. As a result, during the summer, real evapotranspiration even comes close to its potential rate. The water need for optimal crop growth was computed by the model. For the Flumini basin a higher water volume was necessary to satisfy plant demand. This is due mostly to the different rainfall regime (precipitation is higher in the Mogoro basin) and to other differences between the two basins, such as soil characteristics. 


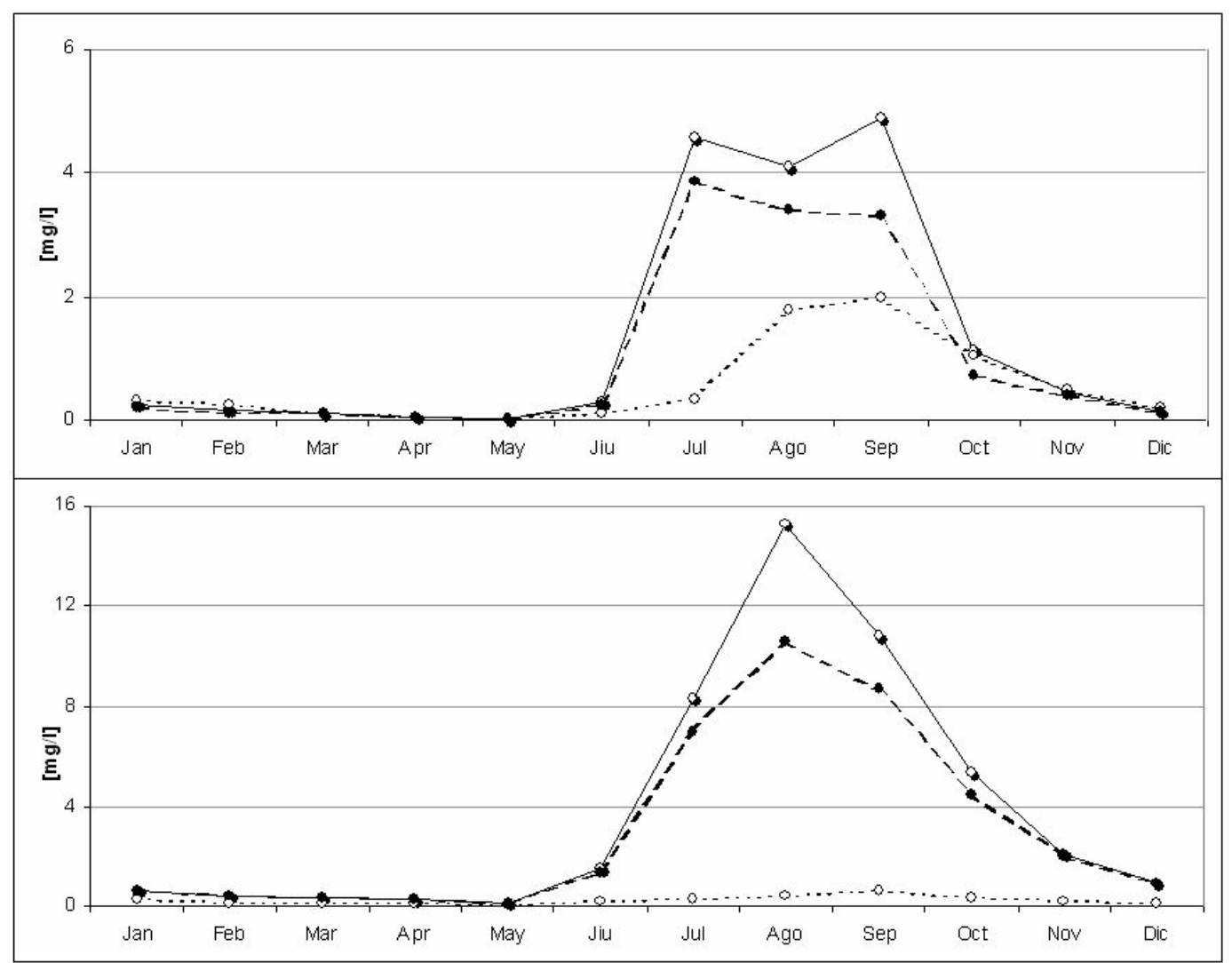

Fig. 7. Nitrate concentrations for the Flumini Mannu (above) and Mogoro Diversi (below) rivers for case 1 (dotted line), case 2 (solid line), and case 3 (dashed line).

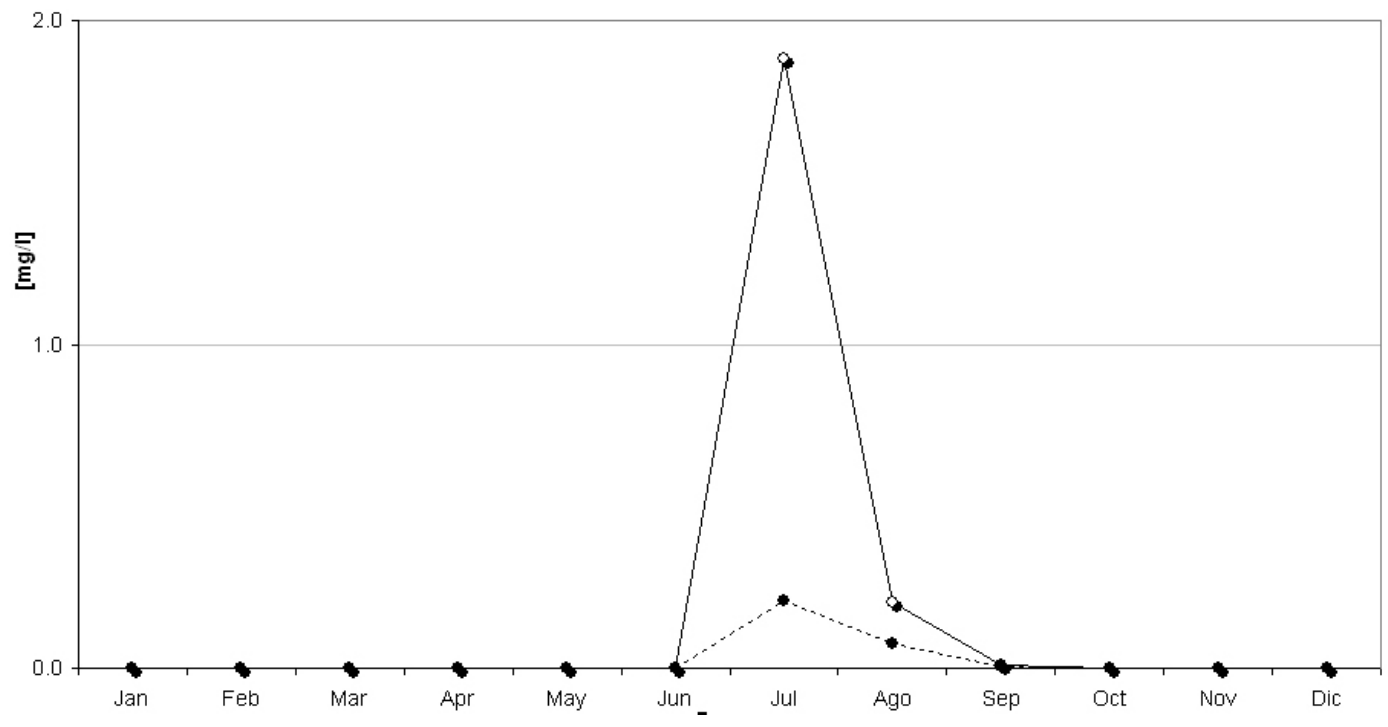

Fig. 8. Pesticide concentrations for the Flumini Mannu (dotted line) and Mogoro Diversi (solid line) rivers.

The fate and transport of nutrients and pesticides in a watershed depend on the transformations the compounds undergo in the soil and stream environment. In general nutri- ents and pesticides that enter the soil layers and the rivers are neither homogeneous in space nor constant in time, and are strongly conditioned by irrigation strategies, land 
Table 2. The metacriteria and indicators for the Arborea application, together with the "raw" values (before standardization to a common scale) of the indicators for each of the four options being analyzed and the weights assigned to each indicator.

\begin{tabular}{|c|c|c|c|c|c|c|}
\hline Indicators & Option 1 & Option 2 & Option 3 & Option 4 & Metacriteria & Weight \\
\hline Nutrient levels in the rivers $(\mathrm{mg} / \mathrm{l})$ & 3.48 & 3.07 & 1.35 & 1.05 & Environmental & 0.2 \\
\hline Pesticide levels in the rivers $(\mathrm{mg} / \mathrm{l})$ & 0.0174 & 0.017 & 0.0024 & 0.0021 & Environmental & 0.2 \\
\hline Mean streamflow $\left(\mathrm{m}^{3} / \mathrm{s}\right)$ & 4.15 & 4.16 & 4.56 & 4.59 & Environmental & 0.15 \\
\hline Streamflow standard deviation & 1.29 & 1.29 & 1.67 & 1.67 & Environmental & 0.1 \\
\hline $\begin{array}{l}\text { Water volume needed for irrigation } \\
\text { (mm/year) }\end{array}$ & 64.5 & 64.5 & 140.9 & 140.9 & Environmental & 0.05 \\
\hline Total cost (EURO) & 1300000 & 1104000 & 1353900 & 1143900 & Economic & 0.05 \\
\hline Cost/load (for irrigation water) (EURO) & 100000 & 258000 & 383500 & 563600 & Economic & 0.05 \\
\hline $\begin{array}{l}\text { Risk for farmers and social conflict } \\
\text { between users (high, } 0 \text { to low, } 1 \text { ) }\end{array}$ & 0.6 & 0.2 & 0.8 & 0.4 & Socio-economic & 0.1 \\
\hline Potential income losses/gains (high, 0 to low, 1) & 0.6 & 0.3 & 0.7 & 0.4 & Socio-economic & 0.1 \\
\hline
\end{tabular}

management practices, meteorological stresses, and soil and stream physical characteristics. Simulated values show that their peak summer concentrations are higher in the Mogoro river for the two land exploitation cases than in the Flumini river (Figs. 7 and 8). This may be due to the longer subsurface and overland flow pathways and the higher water volumes discharged by the larger Flumini basin, thereby diluting contaminants to a lower concentration, and to greater runoff in the Mogoro basin due to its higher rainfall. For pesticides, given identical plant morphology and pesticide solubility characteristics assigned to the $20 \mathrm{~km}^{2}$ parcels in the two basins, the fraction washed off will be a function of the timing and intensity of rainfall events (in the model wash-off will occur when the amount of precipitation on a given day exceeds $2.54 \mathrm{~mm}$ ). The peak nutrient and pesticide concentrations for both basins occurs in the dry summer season, as is to be expected since this corresponds to the period when flows are lowest, temperatures highest, and agricultural activities most intense. The fate of nutrients in the stream environment will depend strongly on temperature, dissolved oxygen (DO) and algal photosynthesis/respiration. In fact DO concentrations increase with turbulence and decrease when temperature increases. In aerobic water, there is a stepwise transformation from organic nitrogen to ammonia, to nitrite, and finally to nitrate. The phosphorus cycle is similar to the nitrogen cycle (the death of algae transforms algal phosphorus into organic phosphorus which can be mineralized to soluble phosphorus and made available for uptake by algae, or may be removed from the stream by settling).

The presence of the treatment plant has the main effect of lowering the concentration of pollutants in both rivers. Waters routed to the stream, in the simulation, are less polluted than the waters of the streams. This also suggests that in the summer, point source pollution can become predominant in semiarid region due to the low level of natural streamflows.

\subsection{DSS application}

The European Union Water Framework Directive aims to ensure that water use or management decisions take into account the views of the many stakeholders who will be impacted by the decision, in order to assess as fully as possible these impacts and identify appropriate future responses as necessary. To support such an assessment, the mDSS is applied to evaluate the water use options based on estimates of pertinent environmental and socio-economic indicators or criteria. For the Arborea study these indicators are the states identified earlier in the DPSIR chain, and we grouped them into metacriteria and criteria (Table 2). A hierarchical structure is adopted so as to assign to the environmental, social, and economic criteria different weights in the analysis. The weights we used in this study are the outcome of discussions with various local stakeholders, municipalities, and water managers, and reflect their perception of the environmental problem at hand. The weights we assigned are $0.7,0.2$, and 0.1 respectively for the environmental, social, and economic metacriteria.

The water quality and quantity indicators are model outputs estimated at the outlet of the basins, and they assess the environmental impacts on the coastal lagoons. The water volume needed for optimal crop growth is estimated by SWAT based on daily soil water deficits that depend on computed soil water content. The economic indicators are derived calculating the value of the water that can be re-used and the cost of the pipeline network to route water to the treatment plant and from the treatment plant to the Mogoro and Flumini basin, as described in a previous section. The social indicators are estimated on the basis of qualitative assessments made from the stakeholder responses to questionnaires. Before proceeding to an evaluation of the different options, the values for the various indicators have to be made comparable, i.e. transformed to a common scale. The mDSS utilises a linear transformation method (the score range method) for 


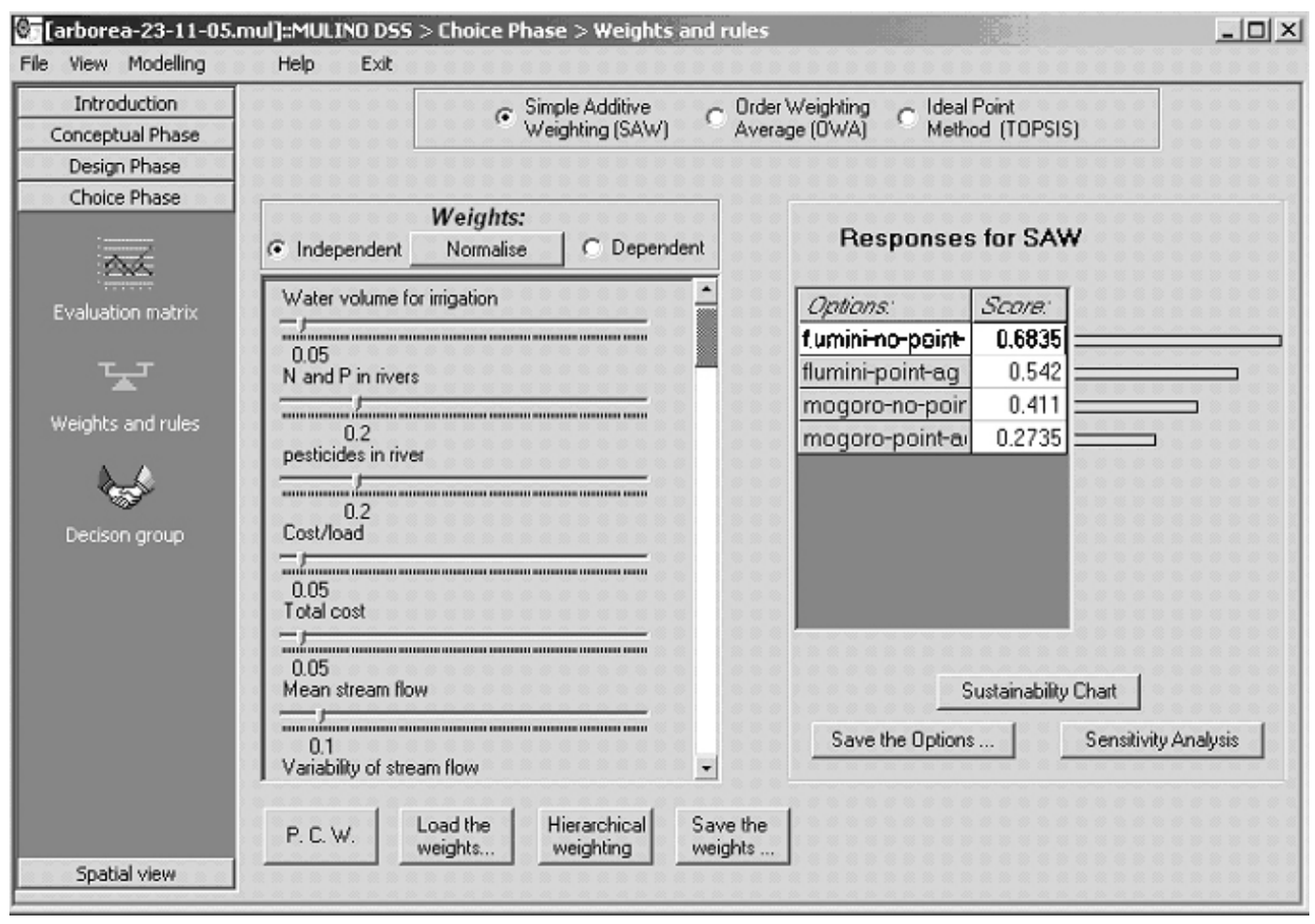

Fig. 9. The mDSS interface. In order to evaluate the options, the simple additive weighting (SAW) method was used. The results indicate that option 3, the Flumini basin with wastewater reuse ("flumini-no-point-ag") is best, with a score of 0.6835.

this standardization procedure, scaling all values in the interval $[0,1]$.

After standardization, the relative performance of the four options is assessed using a value/utility function. The value function is a mathematical representation of human judgements. It translates the performances of the options into value scores, which represent the degree to which decision objectives are attained. The simple additive weighting method (SAW) in mDSS is then used to obtain an aggregate or global score for the different options (Fig. 9) and to examine how changing the weights affects the scores.

The land use options involving the Flumini basin (options 3 and 4) scored highest, with option 3 (wastewater reuse) giving a more favorable outcome compared to option 4. The Flumini options scored higher than the Mogoro options mainly because of environmental criteria (lower pesticide and nutrient levels and a slightly higher mean streamflow). Option 3 scored higher than option 4 mainly on account of socio-economic criteria, as diffuse pollution from land management practices is little affected by the reuse of water or routing this water to the stream. These socio-economic indicators reflect how stakeholders and managers perceive the problem at hand, valuing highly the concept of wastewater reuse due to water scarcity (common in Mediterranean areas) and due to widespread problems with contaminated waters from point and nonpoint releases of contaminants.

\section{Conclusions}

Land use changes and irrigation schemes need to be managed so as to minimize the risk of water and soil contamination and to allocate available water as efficiently as possible without adverse impacts on downstream uses. Water resources management is a complex task that requires data, often in very qualitative form, from different disciplines. Amongst these disciplines, hydrologic simulation models can provide inputs to the decisional process that relate to water quality and quantity in soils and streams in response to different land exploitation schemes. Once translated into indicators or criteria that are pertinent to the problem at hand, the data and other information from various sources can be analyzed in a decision support system to evaluate which management options are best under given circumstances, and to examine how sensitive the DSS results are to various factors, such as the distribution of relative weights.

In this study we applied a watershed hydrological model and a multicriteria DSS to investigate alternative water and land use proposals for the Arborea coastal region in Sardinia. The issues addressed concern the need to shift intensive agriculture and dairy farming activities away from a coastal plain, where adverse impacts on aquifers and lagoons have been documented, to a nearby watershed where more favourable conditions are deemed to exist. Two possible watersheds were investigated, together with the option of 
reutilizing treated wastewater for crop irrigation. The physical processes associated with water movement, crop growth, and nutrient cycling were considered in the distributed hydrological model, as these are essential to simulating the gradual build-up of pollutants due to different land management practices. Based on a weighting distribution that emphasized the environmental criteria derived from the hydrological model (in part because of lack of concrete data on socio-economic parameters), the DSS analysis showed the larger of the two watersheds to be the most favourable site for the land use relocation. This by no means exhaustive analysis nonetheless illustrates the manner in which a decision support system can be applied to a regional water management problem and how hydrologic simulations can usefully contribute quantitative estimates needed in multicriteria analyses.

Acknowledgements. This work has been partially funded by the European Commission (contract EVK1-CT-2000-00082) and by the Sardinian Regional Authorities.

Edited by: L. A. Swatuk

\section{References}

Abel, D. J., Yap, S. K., Ackland, R., Cameron, M. A., Smith, D. F., and Walker, G.: Environmental decision support system project: an exploration of alternative architectures for geographical information systems, Int. J. Geogr. Inf. Syst., 6(3), 193-204, 1992.

Arangino, F., Aru, A., Baldaccini, P., and Vacca, S.: I suoli delle aree irrigabili della Sardegna, Piano Generale delle Acque, Regione Autonoma della Sardegna, Cagliari, Italy, 1986.

Aru A., Baldaccini P., and Vacca S.: Nota illustrativa alla carta dei suoli della Sardegna, con carta illustrata 1:250.000, Regione Autonoma della Sardegna, Cagliari, Italy, 1991.

AATO: Piano d'Ambito, (http://www.ato5acqua.toscana.it/), Autorità d'Ambito, 2001.

Cau, P., Cadeddu, A., Gallo, C., Lecca, G., and Marrocu, M.: Estimating available water resources of the Sardinian island using the SWAT model, in: Proceedings of the Second International SWAT Conference, Bari, Italy, 2002.

Chowdary, V. M., Rao, N. H., and Sarma, P. B. S.: Decision support framework for assessment of non-point-source pollution of groundwater in large irrigation projects, Agr. Water Manage., 75(3), 194-225, 2005.

De Groen, M. and Savenije, H. G.: Markov chains at daily timesteps, key to transpiration at monthly timesteps, in: 1st WARFSA/WaterNet Symposium: Sustainable Use of Water Resources, Maputo, Mozambique, 2000.
Di Luzio, M., Srinivasan, M., and Arnold J.: ARCVIEW Interface for SWAT2000 - User's Guide, USDA Agricultural Research Service, Temple, Texas, 2001.

EAF (Ente Autonomo del Flumendosa): Studio dell'Idrologia Superficiale della Sardegna (SISS), Cagliari, Italy, 1996.

EEA: CORINE Project, http://dataservice.eea.eu.int/dataservice/, 2000.

Eckhardt, K. and Arnold, J. G.: Automatic calibration of a distributed catchment model, J. Hydrol., 251(1-2), 103-109, 2001.

Fedra, K. and Jamieson, D. G.: An object-oriented approach to model integration: a river basin information system example, in: Application of Geographic Information Systems in Hydrology and Water Resources Management, 669-676, IAHS Press, Institute of Hydrology, Wallingford, UK, 1996.

Giupponi, C., Mysiak J., Fassio, A., and Cogan, V.: MULINODSS: a computer tool for sustainable use of water resources at the catchment scale, Mathematics and Computers in Simulation, 64, 13-24, 2004.

Heinemann, A. B., Hoogenboom, G., and de Faria, R. T.: Determination of spatial water requirements at county and regional levels using crop models and GIS: An example for the State of Parana, Brazil, Agri. Water Manage., 52(3), 177-196, 2002.

Leonard, R. A., Kniseland, W. G., and Still, D. A.: GLEAMS: groundwater loading effects on agricultural management systems, Transactions ASAE, 30, 1403-1428, 1987.

Milano, V.: Acquedotti, Hoepli, Milano, Italy, 1996.

Mysiak, J., Giupponi, C., and Rosato, P., Towards the development of a decision support system for water resource management, Environmental Modelling Software, 20, 203-214, 2005.

Neitsch, S. L., Arnold, J., Kiniry, J. R., and Williams, J. R.: Soil and Water Assessment Tool (SWAT) - Theoretical Documentation, USDA Agricultural Research Service, Temple, Texas, 2001.

Nicks, A. D.: Stochastic generation of the occurrence, pattern and location of maximum amount of daily rainfall, in: Proc. Symp. Statistical Hydrology, 154-171, USDA Misc. Publ. 1275, U. S. Gov. Print Office, Washington, DC, 1974.

Sharpley, A. N. and Syers, J. K.: Phosphorus inputs into a stream draining an agricultural watershed: II. Amounts and relative significance of runoff types, Water Air Soil Poll., 11, 417-428, 1979.

USDA and NRCS Soil Survey Division: State Soil Geographic (STATSG0) Data Base - Data Use Information, Miscellaneous Publication No. 1492, 1994.

Vandenberghe, V., van Griensven, A., and Bauwens, W.: Sensitivity analysis and calibration of the parameters of ESWAT: Application to the river Dender, Water Sci. Technol., 43(7), 295-301, 2001.

Watkins Jr., D. W. and McKinney, D. C.: Recent developments associated with decision support systems in water resources, in: U.S. National Report to International Union of Geodesy and Geophysics 1991-1994: Contributions in Hydrology, 941-948, American Geophysical Union, Washington, DC, 1995. 